\title{
Postneoadjuvant Therapy Stage IIIB Esophageal Adenocarcinoma AJCC v8
}

National Cancer Institute

\section{Source}

National Cancer Institute. Postneoadjuvant Therapy Stage IIIB Esophageal

Adenocarcinoma A/CC v8. NCI Thesaurus. Code C133437.

Stage IIIB includes: (T3, N1, M0); (TO-3, N2, M0); (T4a, NO, MO). TO: No evidence of primary tumor. T1: Tumor invades the lamina propria, muscularis mucosae, or submucosa. T2: Tumor invades the muscularis propria. T3: Tumor invades adventitia. T4a: Tumor invades the pleura, pericardium, azygos vein, diaphragm, or peritoneum. N0: No regional lymph node metastasis. N1: Tumor with metastasis in one or two regional lymph nodes. N2: T umor with metastasis in three to six regional lymph nodes. M0: No distant metastasis. (AJCC 8th ed.) 